\title{
Análise de atenuação do sinal gamaespectrométrico em região de floresta com auxílio do índice de vegetação NDVI
}

\author{
Guilherme Ferreira da SIlva, Serviço Geológico do Brasil - CPRM; Michelle Cunha Graça, Serviço Geológico do Brasil - \\ CPRM;
}

Copyright 2017, SBGf - Sociedade Brasileira de Geofísica

This paper was prepared for presentation during the $15^{\text {th }}$ International Congress of the Brazilian Geophysical Society held in Rio de Janeiro, Brazil, 31 July to 3 August, 2017.

Contents of this paper were reviewed by the Technical Committee of the $15^{\text {th }}$ International Congress of the Brazilian Geophysical Society and do not necessarily represent any position of the SBGf, its officers or members. Electronic reproduction or storage of any part of this paper for commercial purposes without the written consent of the Brazilian Geophysical Society is prohibited.

\section{Resumo:}

Dados radiométricos fornecem importante informação sobre a composição do material em superfície, seja rochoso ou não. O processamento destes dados requer reduções matemáticas que transformem o dado bruto lido em picos de energia para concentração equivalente destes elementos químicos. Porém, a presença de umidade e de vegetação inibe a propagação deste sinal radiométrico, comprometendo as interpretações posteriores ou causando falsamente anomalias de baixa concentração destes elementos justamente onde há esta cobertura vegetal. Portanto, o estudo da atenuação causada, assim como correções para este efeito fazemse necessárias como um próximo passo no uso de dados gamaespectrométricos.

\section{Introdução:}

Potássio, urânio e tório são os únicos elementos químicos de ocorrência natural cujo decaimento radioativo produz radiação gama com energia e intensidade suficientes para serem medidas em aerolevantamentos (MINTY, 1997). Devido a este fato, associado a constatação de que os isótopos radiogênicos destes três elementos se distribuem igualmente entre os isótopos estáveis dos mesmos na natureza, a aerogamaespectrometria é uma ferramenta importante para o mapeamento geológico moderno e para comparações qualitativas de concentrações e distribuição destes elementos na superfície.

A realidade da região amazônica muitas vezes restringe o acesso a boas exposições de rocha, quer seja por não haver acesso a estas, ou pela intensa cobertura vegetal. Portanto, o uso de dados aerogeofísicos é uma importante ferramenta para 0 avanço regional geocientífico.

O processamento dos dados derivados da aerogamaespectrometria não é trivial e depende de uma série de fatores ambientais que devem ser corrigidos para uma interpretação normalizada, por exemplo, pela altura de voo, umidade do ar e do solo e a presença de vegetação (IAEA, 2003).

Umidade e cobertura vegetal são duas características intrínsecas da região amazônica, portanto estes dois fatores devem ser considerados quando se planeja um aerolevantamento na região. Contudo, em localidades onde há grandes áreas desmatadas dispostas em conjunto com faixas de vegetação (como por exemplo, estados de Rondônia, Mato Grosso, Tocantins e leste do Pará) é possível verificar a atenuação do sinal nos mapas de radioelementos marcada claramente em regiões de floresta, em detrimento das regiões desmatadas (Figura 1).

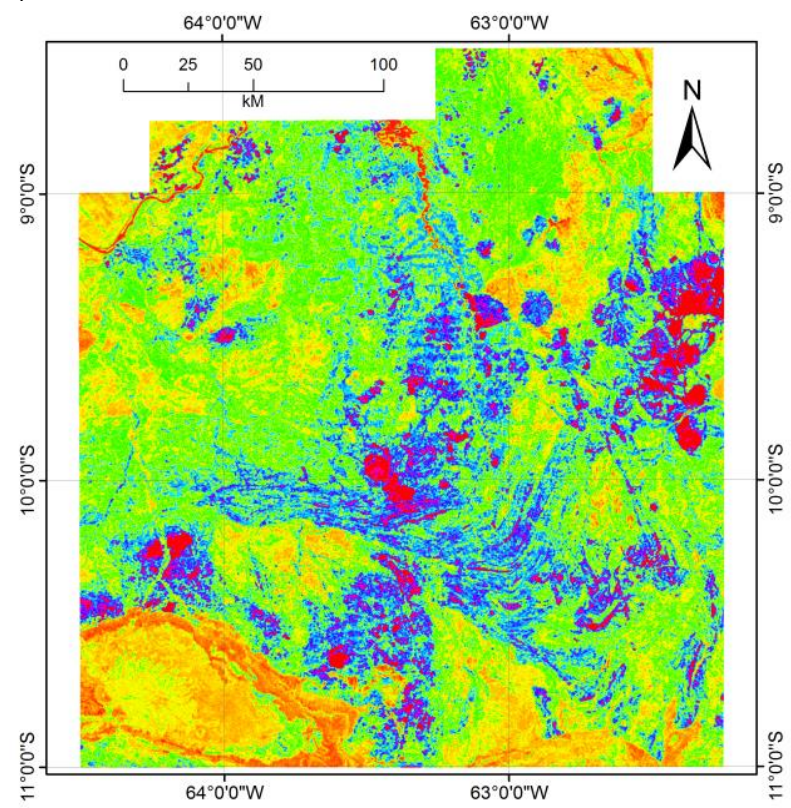

Figura 1: Mapa do Canal da Contagem Total do aerolevantamento Rondônia Central (LASA, 2010). O efeito de direção leste-oeste percebidos em parte do mapa corresponde a regiões com resquício de vegetação original interposta a áreas desmatadas a partir de estradas planejadas (localmente conhecidas como Linhas, no estado de Rondônia).

A vegetação causa um duplo efeito de atenuação nos dados radiométricos, tendo em vista a absorção de radiação pela biomassa da floresta amazônica (efeito retentor) e o erro de processamento onde se toma a copa das árvores como distância entre o sensor e a fonte (efeito processual), este último sendo causado pela subestimação da altura real de voo, uma vez que esta é medida pelos radares sob a copa das árvores ao invés de obter a altura de voo em relação ao solo.

\section{Metodologia:}

Este trabalho discorre sobre o fenômeno da atenuação causada pela floresta, através da análise do aerolevantamento Rondônia Central (LASA, 2010), numa região próxima à cidade de Ariquemes $(\mathrm{RO})$. A área de 
trabalho corresponde a um retângulo de $15 \mathrm{~km}$ de largura e $12 \mathrm{~km}$ de comprimento, contendo um conjunto de 3353 medidas de radiação gamaespectrométrica. As medidas foram espaçadas em 80 metros na direção norte-sul e 500 metros na direção leste-oeste (arranjo do aerolevantamento). O método interpolador utilizado para todos os mapas foi o de "Mínima Curvatura", com células de 125 metros.

O primeiro passo para a verificação do efeito retentor no sinal consistiu na verificação da atenuação através do comparação dos dados radiométricos com o índice de vegetação NDVI (Índice Normalizado da Diferença de Vegetação), criado com base na imagem do sensor TM, do satélite LANDSAT 5 (Figura 2). A imagem foi convertida para um arquivo $X Y Z$ contendo as coordenadas e o número digital do NDVI e posteriormente este arquivo foi convertido para um banco de dados no formato geosoft (.gdb), interpolada para coincidir com a resolução do aerolevantamento e incorporada ao banco de dados original, para efeito de comparação.

Desconsiderando-se os valores de NDVI negativos (cicatrizes de queimada e outras anomalias), a partir da análise dos dados em diagrama de dispersão entre o MDT e o NDVI (Figura 3) é possível identificar quatro populações distintas, claramente divididas em função do índice.

A população correspondente à "Floresta", cujo índice de vegetação varia de 0,6 a 1,0, corresponde à porção responsável por maior parte da atenuação do sinal gamaespectrométrico. As demais populações, caracterizadas como "Campo", cujo NDVI varia de 0,25 a 0,59 e "Pasto", cujo NDVI varia de 0,06 a 0,24 se aproximam gradativamente da população considerada como "Não vegetadas", com índice próximo a zero. Através desta classificação, criou-se um canal de máscara dentro do banco de dados, separando as populações de acordo com essas quatro classes.

O erro processual pode ser corrigido obtendo-se o tamanho médio das árvores na região e posteriormente somando este valor a altura de voo. Considerando a variação topográfica relativamente nula por se tratar de uma região de Superfície Regional de Aplainamento (SEPLAN, 1999), a bimodalidade encontrada no histograma de MDT deve-se a diferença entre o nível do terreno e a altura média da copa das árvores. Este valor, para a área de trabalho, foi correspondente a 16 metros ( $\pm 3 \mathrm{~m}$, de resolução do sensor). Tal valor encontra-se de acordo com a descrição de florestas de terra firme (HAUGAASEN \& PERES, 2006). A variação causada por este erro pode ser calculada pela substituição da altura nominal do aerolevantamento (100 metros) pela altura real em regiões com cobertura de floresta $(116 \mathrm{~m} \pm 3)$ na fórmula de cálculo da radiação à distância (IAEA, 2003)

$$
\mathrm{N}_{\mathrm{H}}=\mathrm{N}_{0} \cdot \mathrm{e}^{-\mu \mathrm{H}} \text { (1) }
$$

- $\mathrm{NH}$ é a radiação à distância $\mathrm{H}$ da fonte,

- No é a radiação na superfície do terreno

- $\mu$ é o coeficiente de atenuação atmosférica.

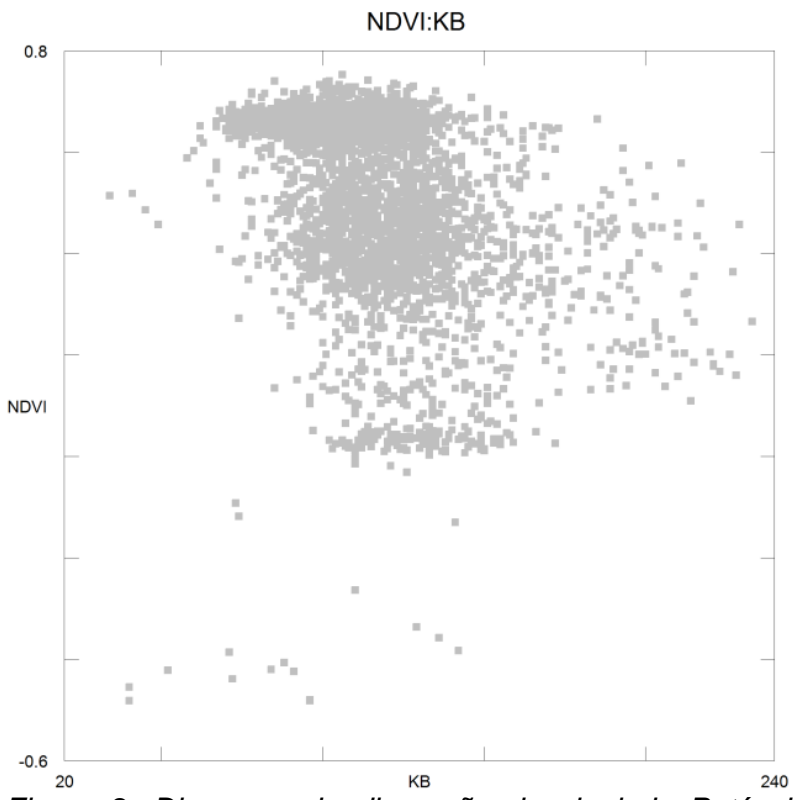

Figura 2: Diagrama de dispersão do sinal do Potássio bruto (KB) em função do índice de vegetação (NDVI).

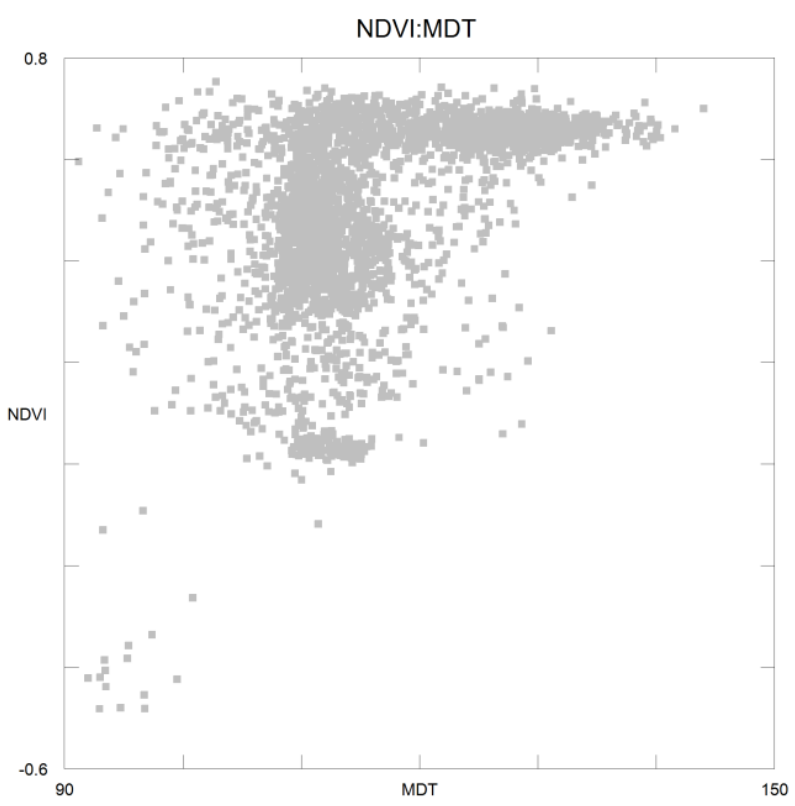

Figura 3: Diagrama de dispersão relacionando o índice de vegetação (NDVI) em função do modelo digital de elevação (MDT).

Tal análise retorna um valor relativo de atenuação da ordem de $15 \%$ para concentrações de potássio, $11 \%$ para concentrações de tório equivalente e 13\% para concentrações de urânio equivalente, na região do aerolevantamento. Os valores de concentração de radioelementos em região de floresta foram inicialmente ajustados levando em conta estes valores

Após a correção do erro processual, assume-se que toda e qualquer atenuação restante é produto da absorção 
causada pela biomassa. Estabelecendo a hipótese de que o sinal radiométrico original corresponde àquele sem a atenuação causada pela cobertura vegetal, ou seja, ao sinal da população onde o NDVI é próximo de zero, e observando que há uma correlação linear com coeficiente angular negativo quando se compara o sinal radiométrico com o NDVI, aplicou-se um fator multiplicador visando equalizar a mediana das populações vegetadas a aquela da população não vegetada.

\section{Resultados:}

O resultado obtido corresponde a ambas as correções é de algum modo satisfatório, tendo reduzido em mapa a presença do efeito atenuador nas regiões de floresta. Porém, o resultado acrescenta ao mapa final um ruído pontual indiscriminado, ressaltando também a direção de linhas de vôo (norte sul).

Os dados corrigidos apresentam uma aproximação estatística do grupo "Não Vegetado", com medianas próximas numericamente, porém com desvios padrões, máximos e mínimos distintos (Quadro 1). Tal efeito é devido, inicialmente, a não exclusão dos dados considerados anômalos (outliers) ou com concentração muito superior ou inferior à mediana. É possível que estes valores sejam os responsáveis pela adição deste ruído.

Outra possibilidade é que este ruído seja produto da adição de um valor com erro associado, como a altura média das árvores, no processamento de correção de erro processual. Porém, devido a ser de natureza exponencial e multiplicado por um número de ordem de grandeza de 10-4 (coeficiente de atenuação $\mu$ ), interpreta-se aqui que essa grandeza não é a responsável pelo problema, pois a variação causada seria muito sutil para a percepção em mapa.

De todo modo, a redução da correlação entre as regiões aparentemente empobrecidas em radioelementos com as regiões de alto índice de vegetação é notável (Figura 4), funcionando melhor para regiões com a geologia mais simples.

\section{Quadro 1: Sumário estatístico do processamento}

\begin{tabular}{|c|c|c|c|c|c|c|}
\hline Elem. & Parâmetro & Florst. & Campo & Pasto & Não Veg. & Corr. \\
\hline \multirow{5}{*}{$\begin{array}{l}\frac{0}{0} \\
\frac{0}{\circ}\end{array}$} & População & 1476 & 1546 & 219 & 126 & 3336 \\
\hline & Mínimo (ppm) & 65 & 85 & 12.97 & 25.46 & 4.42 \\
\hline & Máximo (ppm) & 76.56 & 88.69 & 89.48 & 48.41 & 111.83 \\
\hline & Mediana (ppm) & 25.25 & 32.37 & 37.53 & 37.12 & 37.06 \\
\hline & Dsvpad (ppm) & 6.76 & $\lambda$ & 19.49 & .59 & 12.04 \\
\hline \multirow{5}{*}{$\begin{array}{l}\frac{0}{\sqrt{\alpha}} \\
\text { 这 } \\
\text { O }\end{array}$} & População & 1476 & 1546 & 219 & 126 & 3336 \\
\hline & Mínimo (ppm) & 30 & 34 & 35 & 97 & 36.38 \\
\hline & Máximo (ppm) & 193 & 229 & 233 & 172 & 245.00 \\
\hline & Mediana (ppm) & 105 & 121 & 136 & 129.5 & 128.00 \\
\hline & Dsvpad (ppm) & 16.74 & 24.28 & 14.79 & 14.79 & 23.98 \\
\hline \multirow{5}{*}{$\begin{array}{l}\text { 을 } \\
\text { 迹 } \\
\text { 方 }\end{array}$} & População & 1476 & 1546 & 219 & 126 & 3336 \\
\hline & Mínimo (ppm) & -0.481 & 0.26 & 0.64 & 0.85 & -1.17 \\
\hline & Máximo (ppm) & 4.84 & 5.56 & 4.96 & 4.15 & 11.76 \\
\hline & Mediana (ppm) & 1.908 & 2.47 & 2.48 & 2.88 & 3.37 \\
\hline & Dsvpad (ppm) & 0.7 & 0.78 & 0.69 & 0.71 & 1.58 \\
\hline
\end{tabular}

\section{Discussão e Conclusões:}

A atenuação de sinal causada pela região de floresta deve ser considerada para análises quantitativas e qualitativas do produto da aerogamaespectrometria, principalmente em regiões que apresentam porções desmatadas ao lado de porções com vegetação densa, pois a qualidade do dado é afetada assim como ruídos e falsas anomalias poligonizadas são geradas em mapa.

Para o estudo qualitativo de pequenas áreas, como compilações geoestatísticas de pequenas anomalias de concentração de radioelementos (para a prospecção de elementos terras rara, por exemplo), este efeito pode inviabilizar um processamento mais refinado, pois as áreas desmatadas gerariam falsas anomalias e o contorno do corpo anômalo se perderia nas regiões atenuadas.

O erro na estimativa da distância entre o sensor aerotransportado e a fonte de radiação são a causa de até $50 \%$ da atenuação do sinal, portanto deve-se considerar a adição de um sensor radar que seja capaz de ultrapassar a copa das árvores para fornecer a distância real.

Por fim, entende-se que este resultado apresentado não é totalmente satisfatório, mas sugere-se o estudo do problema, seja com dados reais ou através da modelagem de dados sintéticos capazes de oferecer correção definitiva.

\section{Agradecimentos:}

Os autores agradecem Roberto Gusmão de Oliveira pelas críticas a respeito do trabalho quando no seu princípio e a Cassiano Costa e Castro, assessor da Diretoria de Geologia e Recursos Minerais da Residência de Porto Velho, pela autorização e incentivo a elaboração deste trabalho.

\section{Referências:}

HAUGAASEN, T; PERES, C.A. 2006. Floristic, edaphic and structural characteristics of flooded and unflooded forests in the lower Rio Purús region of central Amazonia, Brail. ACTA AMAZONICA, Vol. 36(1) 2006:25-36.

IAEA, 2003. Guidelines for radioelemento mapping using gamma ray spectrometry data. International Atomic Energy Agency, IAEA-TECDOC-1363; Viena, Austria. 179pp.

LASA, 2010. Projeto Aerogeofísico Rondônia Central Relatório final do levantamento e processamento de dados magnetométricos gamaespectrométricos. 168pp.

MINTY, B.R.S, 1997. Fundamentals of airbone gammaray spectrometry. Journal of Australian Geology \& Geophysics, 17(2).39-50.

SEPLAN, 1999. Zoneamento sócio-econômico ecológico do estado de Rondônia. Secretaria de Planejamento do Estado de Rondônia. Texto explicativo e mapas de geomorfologia, vegetação e solos, escala 1:250.000, Porto Velho/RO. 


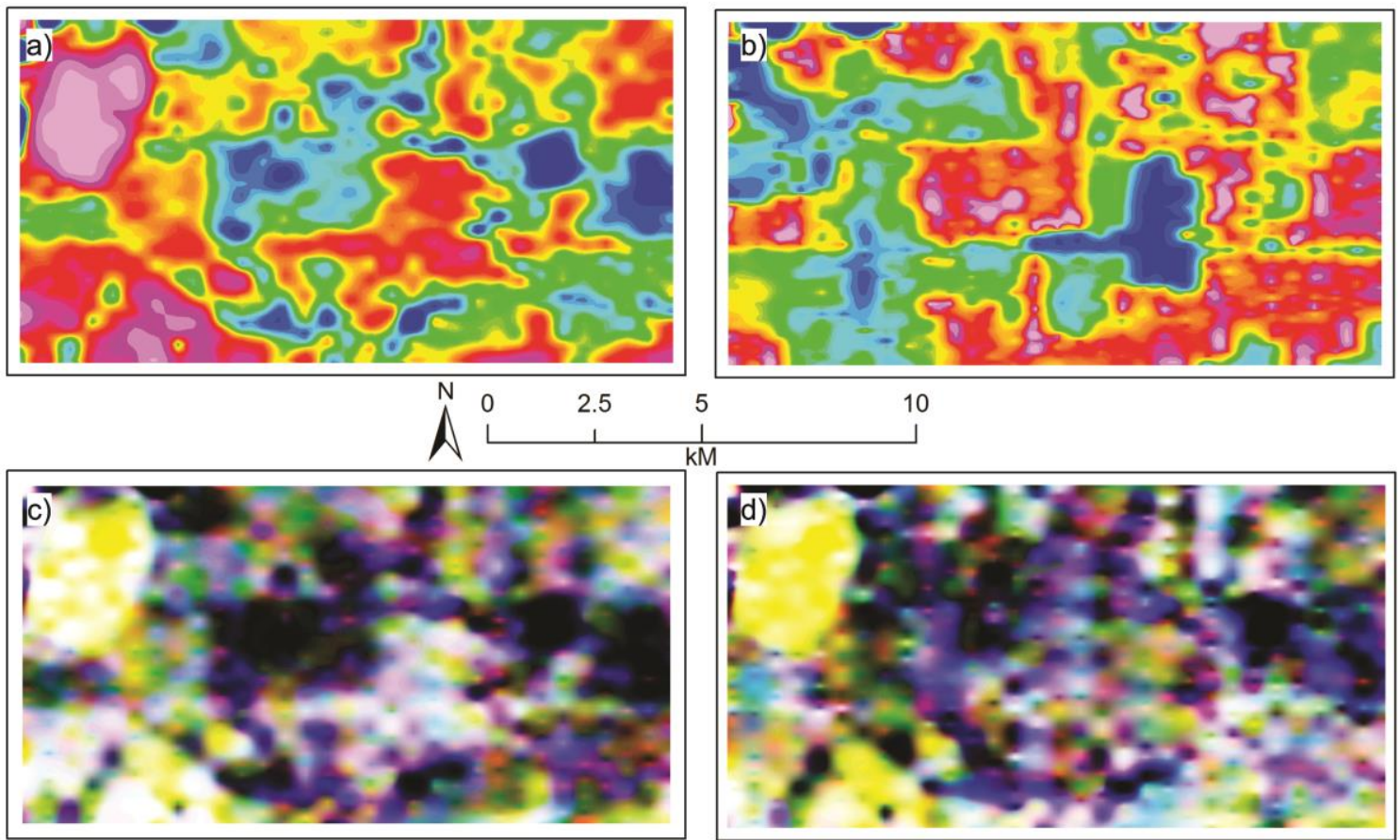

Figura 4: Mapa de concentração de tório equivalente. b) Mapa de índice de vegetação NDVI reamostrado e interpolado para uma malha de 125 metros. c) Mapa ternário RGB de radioelementos antes da correção (Kb, eTh, eU). d) Mapa ternário RGB de radioelemento posterior às correções de erro processual e de retenção 